\title{
Pancreatoblastoma with portal vein involvement in a child: A case report
}

\author{
Hideaki Tanaka ${ }^{1}$, Yoshihiro Kitano ${ }^{1}$, Hajime Takayasu ${ }^{1}$, Satoshi Matuda ${ }^{1}$, Waka Yamada ${ }^{1}$, Mureo \\ Kasahara $^{2}$, Yuki Genma ${ }^{3}$, Chikako Kiyotani ${ }^{3}$, Tetsuya Mori ${ }^{3}$, Kentaro Matsuoka ${ }^{4}$, Atsuko \\ Nakazawa ${ }^{4}$, Yasusi Fuchimoto ${ }^{1}$, Yutaka Kanamori ${ }^{1}$ \\ 1. Department of Surgical Specialties, Division of Surgery, National Center for Child Health and Development, Okura, \\ Setagaya-Ku, Tokyo, Japan. 2. Department of Transplant Surgery, National Center for Child Health and Development, \\ Okura, Setagaya-Ku, Tokyo, Japan. 3. Department of Oncology, National Center for Child Health and Development, \\ Okura, Setagaya-Ku, Tokyo, Japan. 4. Department of Pathology, National Center for Child Health and Development, \\ Okura, Setagaya-Ku, Tokyo, Japan
}

Correspondence: Hideaki Tanaka. Address: Department of Surgical Specialties, Division of Surgery, National Center for Child Health and Development, 2-10-1 Okura, Setagaya-Ku, Tokyo 157-8535, Japan. E-mail: hideakitnk@hotmail.com

Received: January 5, 2013

DOI : $10.5430 /$ jst.v3n2p44
Accepted: January 28, 2013

URL: http://dx.doi.org/10.5430/jst.v3n2p44

\section{Abstract}

Pancreatoblastoma is a rare pancreatic tumor in children. Its biologic behavior is aggressive with frequent local invasion, recurrence, and metastasis, for which there has been no standard treatment regimen.

A 13-year old Japanese girl had pancreatoblastoma arising from the pancreas head and body and invading the portal vein. The tumor was resected with pancreaticoduodenectomy combined with reconstruction of the portal and splenic vein using native left common iliac vein graft, followed by chemotherapy. The tumor recurred in the liver and periportal lymph node but was treated with surgical resection and chemotherapy followed by autologous peripheral blood stem cell transplantation. The reconstructed portal vein has been patent with no sign of stricture for 3.5 years after the first operation. She has been well with a second complete remission for 10 months.

Complete surgical resection has been considered for long-term survival of patients with pancreatoblastoma. Portal venous involvement is not a contraindication of surgical resection of pancreatic tumors and may be aggressively treated by pancreaticoduodenectomy with portal venous reconstruction using a venous conduit. Autologous peripheral blood stem cell transplantation has been used in only two other pediatric cases in the literature for treating pancreatoblastoma. Although our follow-up period is short, aggressive surgical and chemotherapeutic regimen may hold therapeutic promise for managing advanced or relapsed pancreatoblastoma in children.

\section{I ntroduction}

Pancreatoblastoma is a rare pancreatic tumor, representing the most common pancreatic tumor in early childhood. It usually occurs in children in the first decade of life, although occasional neonatal and adult cases have been reported ${ }^{[1-3]}$. The biologic behavior of pancreatoblastoma is aggressive with frequent local invasion, recurrence, and metastasis ${ }^{[4,5]}$. Complete surgical resection is the key to good prognosis in the absence of metastatic disease ${ }^{[6-8]}$. Chemotherapy and 
radiotherapy are recommended for recurrent, unresectable, or metastatic cases, but there has been no standard regimen so far.

We report here a case of pancreatoblastoma with invasion into the portal vein. After aggressive surgical treatment with portal vein reconstruction followed by chemotherapy, the tumor recurred in the liver and periportal lymph node. Those were treated with resection and chemotherapy followed by autologous peripheral blood stem cell transplantation.

Figure 1. Contrast-enhanced abdominal computed tomography (CT) prior to the primary operation. The huge heterogeneously enhanced mass adjacent to the liver hilum appeared to originate from the head of the pancreas. The tail of the pancreas was spared, but the main pancreatic duct in the tail is slightly dilated.

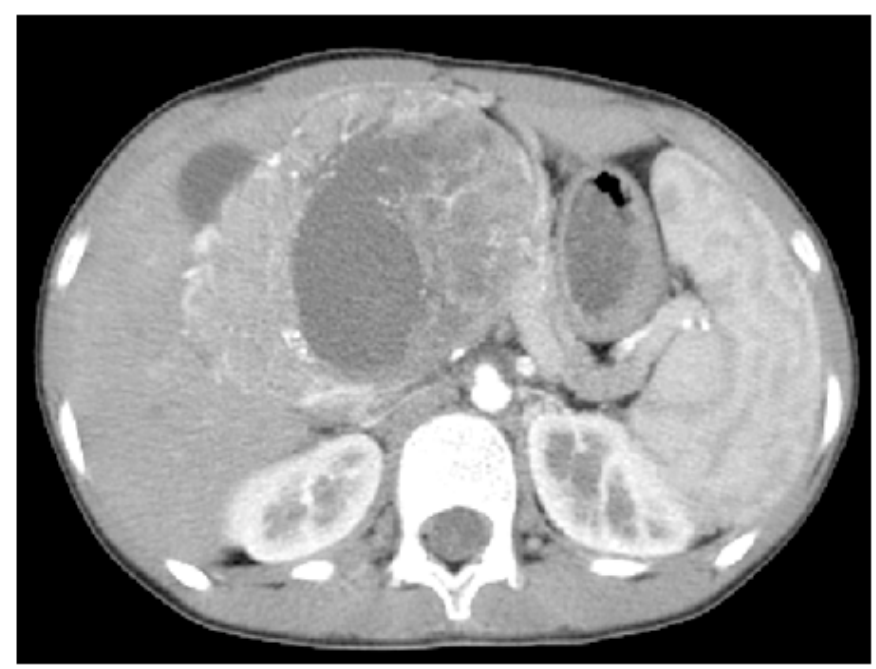

\section{Case presentation}

A 13-year old female was referred to a general practitioner because her health checkup at school found proteinuria. Her abdominal ultrasound revealed an abdominal mass, and she was referred to our hospital. Her vital signs and physical examinations were unremarkable for her age except for a hard, nontender, immobile mass in her right upper quadrant. Laboratory examinations indicated a serum level of alpha-fetoprotein (AFP) of $1.8 \mathrm{ng} / \mathrm{mL}$ (normal: 1.1-6.6 ng/mL), a neuron-specific enolase (NSE) of $28 \mathrm{ng} / \mathrm{mL}$ (normal: $5.7-12 \mathrm{ng} / \mathrm{mL}$ ), CA19-9 of $45.8 \mathrm{U} / \mathrm{ml}$ (normal: $<37 \mathrm{U} / \mathrm{mL}$ ), aspartate aminotransferase of $38 \mathrm{U} / \mathrm{L}$ (normal: 15-30 U/L), alanine aminotransferase of $81 \mathrm{U} / \mathrm{L}$ (normal: 9-28 U/L), lactate dehydrogenase of $328 \mathrm{U} / \mathrm{L}$ (normal: 145-270 U/L), gamma-glutamyl transferase of $185 \mathrm{U} / \mathrm{L}$ (normal: 8-38 U/L), and amylase of $191 \mathrm{U} / \mathrm{L}$ (normal: 44-176 U/L). Contrast-enhanced computed tomography (CT) revealed a huge heterogeneously enhanced mass adjacent to the liver hilum, which appeared to originate from the head of pancreas, and the tail of the pancreas was spared (Figure 1). Occlusion of the main trunk of her portal vain and its cavernous transformation were evident in the CT. No distant metastatic tumor was identified in the preoperative imaging studies. With the setup of whole tumorectomy and vascular reconstruction, incisional biopsy was performed, and the snap-frozen specimen was consistent with pancreatoblastoma. Since the effectiveness of chemotherapy for pancreatoblastoma had not been established, we decided to perform primary resection of the tumor. Occlusion of the portal vein by the tumor invasion ranged from below the bifurcation of the right and left branches of the portal vein to the confluence of splenic and superior mesenteric veins. There was no invasion of the tumor to pylorus or stomach. The tumor was totally resected with pylorus-preserving pancreaticoduodenectomy followed by modified Child's reconstruction. The portal flow was restored using her native left common iliac vein graft. The graft was anastomosed end-to-end to the main portal vein at the hepatic hilum and to the superior mesenteric vein, and the splenic vein was anastomosed end-to-side to the graft (Figure 2). All the anastomoses were performed with running sutures using 6-0 Prolene ${ }^{\mathrm{TM}}$. The operation time was 15 hours and, and blood loss was $2,650 \mathrm{ml}(74 \mathrm{~mL} / \mathrm{kg})$. The histopathological finding of the resected tumor was characterized by highly cellular epithelial tumor cell proliferation and squamoid corpuscles, which was consistent with pancreatoblastoma (Figure 3). 
Figure 2. Reconstruction of the portal vein and superior mesenteric vein with autologous common iliac vein graft

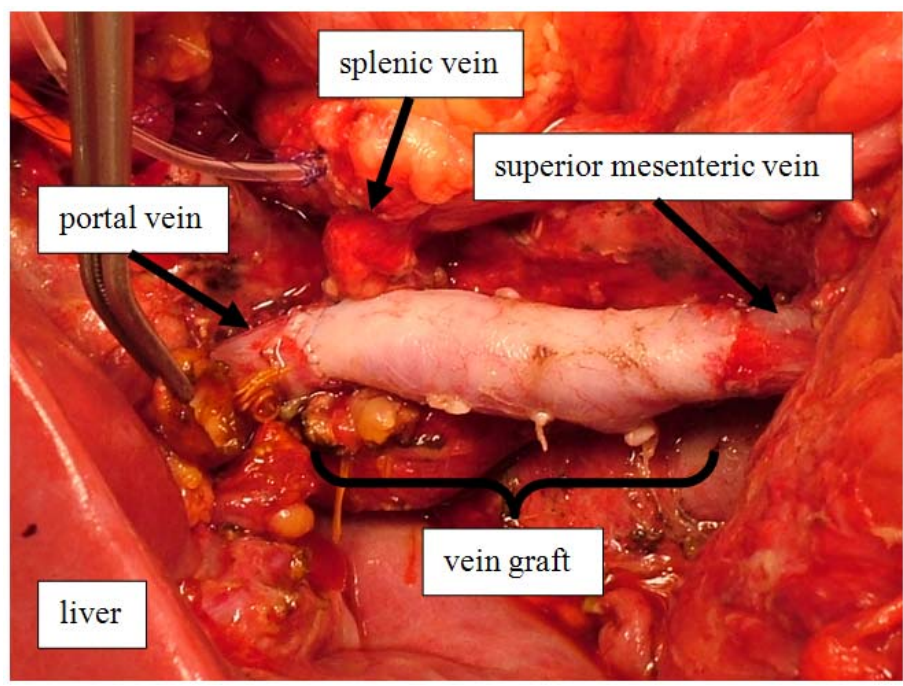

Tumor cells were arranged in solid sheets or as small acini. The patient had no postoperative surgical complications, and the patency of the vein graft was confirmed by Doppler ultrasound and CT. She was treated with adjuvant chemotherapy, one cycle of chemotherapy consisting of cisplatin $80 \mathrm{mg} / \mathrm{m}^{2}$ on day 1 and pirarubicin $30 \mathrm{mg} / \mathrm{m}^{2}$ on days 2 and 3 and two cycles of chemotherapy thereafter consisting of etoposide $100 \mathrm{mg} / \mathrm{m}^{2}$ on days 1 to 5 , cyclophosphamide $1200 \mathrm{mg} / \mathrm{m}^{2}$ on day 1 , cisplatin $90 \mathrm{mg} / \mathrm{m}^{2}$ on day 2, and pirarubicin $40 \mathrm{mg} / \mathrm{m}^{2}$ on day 3. She was discharged 4 months after the operation and was followed closely on an outpatient basis.

Figure 3. Histopathology of the tumor revealed highly cellular epithelial tumor cell proliferation and squamoid corpuscles, which was consistent with pancreatoblastoma.

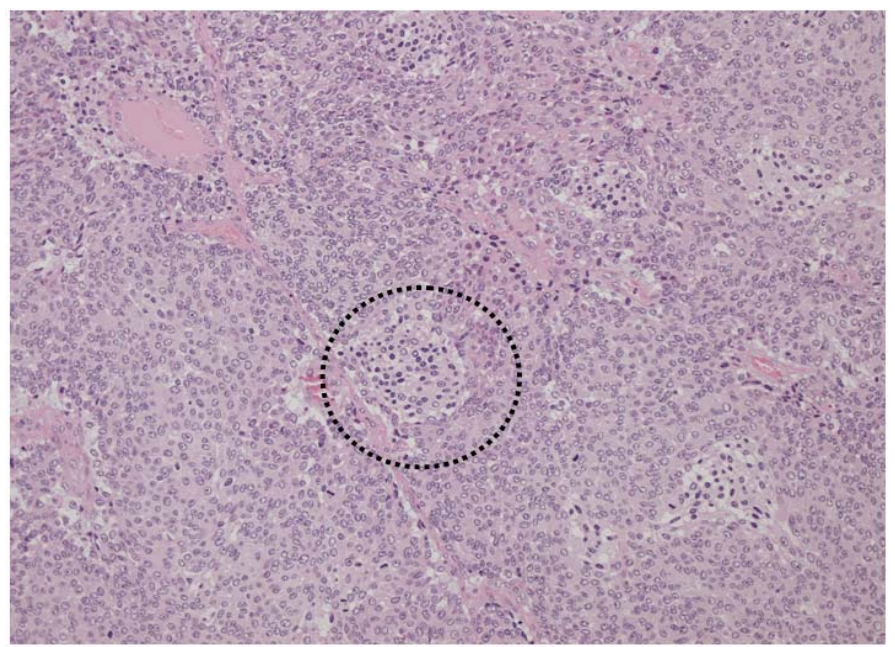

Two metastatic tumors were identified in MRI and CT 2.5 years after the operation. One was $1.5 \mathrm{~cm}$ in diameter located superficially in the right lobe in the liver (Couinaud Segment 7) (Figure 4a), and the other was $2 \mathrm{~cm}$ in diameter in the liver hilum between the proper hepatic artery and the reconstructed portal vein (Figure $4 \mathrm{~b}$ ). These tumors were also detected by Fluodeoxyglucose Positron Emission tomography (FDG PET)/CT (Figure 4c). Serum tumor markers were not elevated. She was readmitted for a second laparotomy. The metastatic tumor in the liver was enucleated with negative surgical margin. The metastatic lymph node at the liver hilum was strictly adherent to the hepatic artery and the portal vein, but was gross-totally resected with meticulous dissection. Those tumors were pathologically confirmed to be recurrences of pancreatoblastoma during the operation. She experienced no complication related to the surgical procedure. Four cycles of 
the above-mentioned latter chemotherapy were administered. After CT indicated no residual tumor, autologous peripheral blood stem cell transplantation (auto-PBSCT) was performed 4 months after the second operation. The conditioning regimen consisted of melphalan $100 \mathrm{mg} / \mathrm{m}^{2}$ (days -9, -8), etoposide $200 \mathrm{mg} / \mathrm{m}^{2}$ (days -7 to -4 ), carboplatin $400 \mathrm{mg} / \mathrm{m}^{2}$ (days -7 to -4 ), and pirarubicin (days -3 and -2). She was discharged 5.5 months after the operation. She has been well for 10 months with complete remission since the second operation, and the vein graft has been patent with no sign of stricture for 3.5 years since the first operation.

Figure 4. $\mathrm{CT}$ at the time of the recurrence. Two masses $(1.5$ and $2 \mathrm{~cm}$ in diameter) with low-level enhancement are noted in the right lobe of the liver (Couinaud Segment 7) (a; Axial view, arrow) and in the liver hilum between the proper hepatic artery and the reconstructed portal vein (b; Coronal view). Axial fused PET/CT image showed intense FDG uptake in the same sites as CT showed the suspected recurrent masses (c).

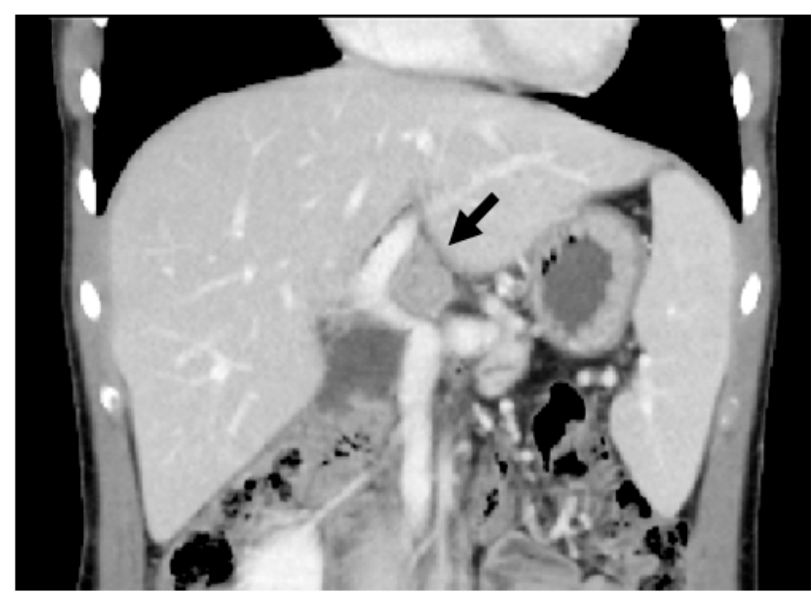

b

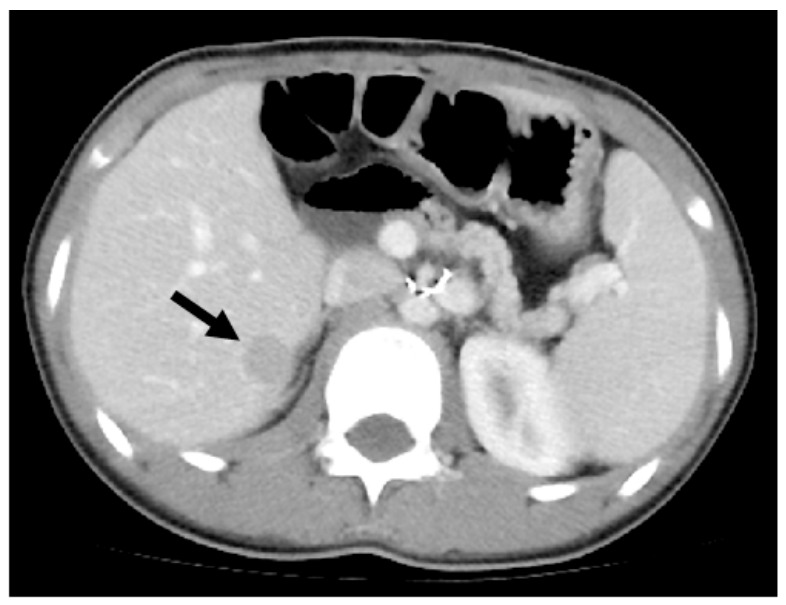

a

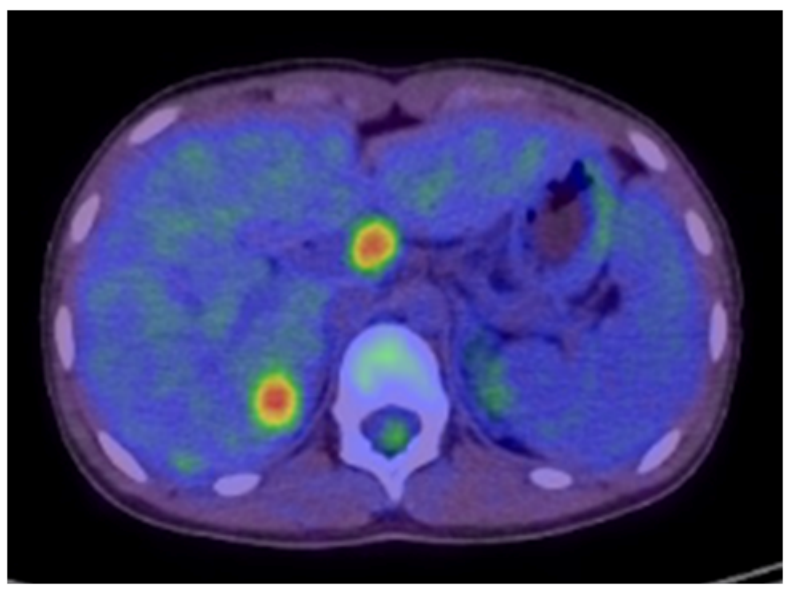

C

\section{Discussion}

Complete surgical resection is the treatment most commonly associated with long-term survival of patients with pancreatoblastoma. Pancreatoblastoma, however, is often unresectable at diagnosis ${ }^{[1]}$. Various regimens of neoadjuvant chemotherapy have been used, aiming at converting an unresectable tumor into a resectable one ${ }^{[8]}$, but it is unknown whether neoadjuvant chemotherapy for pancreatoblastoma ultimately results in an improved survival rate ${ }^{[2]}$. Our case had advanced pancreatoblastoma with portal venous invasion at the initial presentation. We chose primary resection with portal venous reconstruction rather than neoadjuvant chemotherapy with delayed primary resection because we considered that failed response to our trial of neoadjuvant chemotherapy with uncertain efficacy would possibly lead to its growth to a truly unresectable tumor. There currently is no proven indication for adjuvant chemotherapy in successfully resected cases of pancreatoblastoma, whether primary or recurrent ${ }^{[2]}$. A microscopic residual tumor was possible after the two surgeries 
in our case, so we chose to treat our case with adjuvant chemotherapy after the two surgeries, the latter of which was followed by auto-PBSCT. The chemotherapeutic regimen that was recommended by Defachellas ${ }^{[8]}$ as a neoadjuvant chemotherapy to reduce tumor volume in unresectable cases of pancreatoblastoma was cisplatin and doxorubicin. This PLADO regimen was also used as perioperative chemotherapy for pancreatoblastoma in the report from EXPerT ${ }^{[6]}$. Gemcitabine was reported to be effective in decreasing the size of primary and metastatic tumor of pancreatoblastoma to achieve the complete resection ${ }^{[7]}$. Gemcitabine may be one of the promising second-line chemotherapy for pancreatoblastoma. In addition to the adjuvant chemotherapy after the surgery for the recurrence, we used high-dose chemotherapy followed by auto-PBSCT. Auto-PBSCT has been used in only two cases ${ }^{[9,10]}$ in the literature for treating advanced pancreatoblastoma. Yonekura ${ }^{[9]}$ reported the first case of advanced pancreatoblastoma invading the portal vein treated successfully by neoadjuvant chemotherapy and pancreaticoduodenectomy with portal vein reconstruction, followed by auto-PBSCT. Hamidieh ${ }^{[10]}$ also reported a case with relapsed pancreatoblastoma treated by debulking surgery, followed by aggressive chemotherapy and auto-PBSCT as well. Their follow-up periods were 6 and 2 years without recurrence, respectively, and ours is only 10 months. Auto-PBSCT seems to be a promising treatment modality for managing relapsed or advanced stage of pancreatoblastoma, but further studies are needed to confirm the efficacy in obtaining long-term survival.

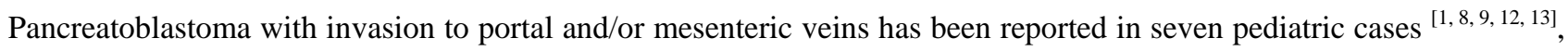
although not all the treatments or the outcomes were well described in those papers. Yonekura ${ }^{[9]}$ reported reconstruction of the portal and superior mesenteric veins using rolled pericardium. Adult pancreatic adenocarcinoma with tumor involvement of the portal vein or superior mesenteric vein without metastatic disease has now been classified as borderline resectable ${ }^{[14]}$. The need for vascular reconstruction did not predict worse outcome compared to patients undergoing standard pancreaticoduodenectomy for adult pancreatic adenocarcinoma ${ }^{[14]}$. Various conduits for the interposition graft to reconstruct portal and superior mesenteric veins have been reported in adult pancreatic adenocarcinoma including internal jugular vein ${ }^{[15]}$, left renal vein ${ }^{[16]}$, external iliac vein ${ }^{[17]}$, femoral vein ${ }^{[14,18]}$, and saphenous vein ${ }^{[19]}$. In our case, the native left common iliac vein was chosen as the conduit because the graft size matched the ends of the portal and superior mesenteric veins. Turley ${ }^{[14]}$ recommended in their adult study that pancreatic surgeons with insufficient vascular surgical experience use a multidisciplinary surgical approach involving a vascular surgeon if necessary to perform pancreaticoduodenectomy with vascular reconstruction, and the same suggestion would be applied to pediatric pancreatoblastoma.

PET/CT has been increasingly viewed as useful, accurate, and cost-effective modality in diagnosing and managing pancreatic cancer ${ }^{[20]}$, but there has been no data to describe the usefulness in pancreatoblastoma. Our case showed intense uptake of FDG in the two recurrent sites, and this may indicate PET/CT is useful in the diagnosis and detecting the recurrence in the follow-up period.

\section{Conflict of interests}

The authors declare that they have no conflict of interests.

\section{References}

[1] Klimstra S, Wenig B, Adair CF, Heffess S. Pancreatoblastoma. A clinicopathological study and review of the literature. Am J Surg Pathol. 1995; 19: 1371-1389. PMid:7503360 http://dx.doi.org/10.1097/00000478-199512000-00005

[2] Shorter N, Glick R, Klimstra D, Brennan M, Laquaqlia P. Malignant pancreatic tumors in childhood and adolescence: The Memorial Sloan-Kettering Experience, 1967 to present. J Pediatr Surg. 2002; 37: 887-892. PMid:12037756 http://dx.doi.org/10.1053/jpsu.2002.32897

[3] Brecht I, Schneider D, Kloppel G, von Schweinitz D, Barthlen W, Hamre M. Malignant pancreatic tumors in children and young adults: evaluation of 228 patients identified through the surveillance, epidemiology, and end results (SEER) database. Klin Padiatr. 2011; 223: 341-345. PMid:22012608 http://dx.doi.org/10.1055/s-0031-1287836 
[4] Perez E, Gutierrez J, Koniaris L, Neville H, Thompson W, Sola J.J Ped Surg. 2009; 44: 197-203. PMid:19159743 http://dx.doi.org/10.1016/j.jpedsurg.2008.10.039

[5] Rojas Y, Warneke C, Dhamne C, Tsao K, Nuchtern J, Lally K, et al. Primary malignant pancreatic neoplasms in children and adolescents: a 20 year experience. J Ped Surg. 2012; 47: 2199-2204. PMid:23217876 http://dx.doi.org/10.1016/j.jpedsurg.2012.09.005

[6] Bien E, Godzinski J, Dall'Igna P, Defachelles A, Stachowicz-Stencel T, Orbach D, et al. Pancreatoblastoma: a report from the European cooperative study group for paediatric rare tumours (EXPeRT). Eur J Cancer. 2011; 47: 2347-2352. PMid:21696948 http://dx.doi.org/10.1016/j.ejca.2011.05.022

[7] Belletrutti M, Bigam D, Bhargava R, Grundy P. Use of Gemcitabine with multi-stage surgical resection as successful second-line treatment of metastatic pancreatoblastoma. J Pediatr Hematol Oncol. 2013; 35: e7-e10. PMid:23042010 http://dx.doi.org/10.1097/MPH.0b013e3182707577

[8] Defachelles AS, Martin de Lassalle E, Boutard P, Nelken B, Schneider P, Patte C.. Pancreatoblastoma in childhood: Clinical course and therapeutic management of seven patients. Med Pediatr Oncol. 2001; 37: 47-52. PMid:11466723 http://dx.doi.org/10.1002/mpo.1162

[9] Yonekura T, Kosumi T, Hokim M, Hirooka S, Kitayama H, Kubota. Aggressive surgical and chemotherapeutic treatment of advanced pancreatoblastoma associated with tumor thrombus in portal vein. J Pediatr Surg. 2006; 41: 596-598. PMid:16516645 http://dx.doi.org/10.1016/j.jpedsurg.2005.11.071

[10] Hamidieh A, Jalili M, Khojasteh O, Ghavamzadeh A. Autologous stem cell transplantation as treatment modality in a patient with relapsed pancreatoblastoma. Pediatr Blood Cancer. 2010; 55: 573-576. PMid:20658635 http://dx.doi.org/10.1002/pbc.22536

[11] Dhebri A, Connor S, Campbell F, Ghaneh P, Sutton R, Neoptolemos P. Diagnosis, treatment, and outcome of pancreatoblastoma. Pancreatology. 2004; 4: 441-453. PMid:15256806 http://dx.doi.org/10.1159/000079823

[12] Gupta A, Mitra D, Berry M, Dinda A, Bhatnagar V. Sonography and CT of pancreatoblastoma in children. Am J Radiol. 2000; 174: 1639-1641.

[13] Montemarano H, Lonergan G, Bulas D, Selby D. Pancreatoblastoma: imaging findings in 10 patients and review of the literature. Radiology. 2000; 214: 476-482. PMid:10671596

[14] Turley R, Peterson K, Barbas A, Ceppa P, Paulson E, Blazer D, et al. Vascular surgery collaboration during pancreaticoduodenectomy with vascular reconstruction. Ann Vas Surg. 2012; 26: 685-692. PMid:22305864 http://dx.doi.org/10.1016/j.avsg.2011.11.009

[15] Christians K, Lal A, Pappas S, Quebbeman E, EvansB. Portal vein resection. Surg Clin N Am. 2010; 90: 309-322. PMid:20362788 http://dx.doi.org/10.1016/j.suc.2009.12.001

[16] Choi S, Hwang H, Kang C, Lee W. Potential use of left renal vein graft in pancreaticoduodenectomy combined with long segmental resection of the superior mesenteric-splenic-portal vein confluence. J Pancreas. 2011; 12: 234-240.

[17] Kaneoka Y, Maeda A, Isogai M. Surgical outcome of autologous external iliac vein grafting in cases of hepato-pancreato-biliary malignancy: how I do it. J Gastrointest Surg. 2012; 16: 1590-1596. PMid:22700369 http://dx.doi.org/10.1007/s11605-012-1933-3

[18] Flemimg J, Barnett C, Clagett P. Superficial femoral vein as a conduit for portal vein reconstruction during pancreaticoduodenectomy. Arch Surg. 2005; 140: 698-701. PMid:16027337 http://dx.doi.org/10.1001/archsurg.140.7.698

[19] Lee D, Mitchell E, Jones M, Landry G, Liem T, Sheppard B, et al. Techniques and results of portal vein / superior mesenteric vein reconstruction using femoral and saphenous vein during pancreaticoduodenectomy. J Vas Surg. 2010; 51: 662-666. PMid:20080375 http://dx.doi.org/10.1016/j.jvs.2009.09.025

[20] Dibble E, Karantanis D, Mercier G, Peller P, Kachnic L, Subramaniam R. PET/CT of cancer patients: Part I , pancreatic neoplasm. AJR. 2012; 199: 952-967. PMid:23096166 http://dx.doi.org/10.2214/AJR.11.8182 